\title{
Electrochemically Active Thin Carbon Films with Enhanced Adhesion to Silicon Substrates
}

Pengfei Niu, ${ }^{1}$ Laura Asturias-Arribas, ${ }^{1}$ Martí Gich, ${ }^{* 1}$ César Fernández-Sánchez, ${ }^{* 2}$ Anna Roig ${ }^{1}$

${ }^{1}$ Institut de Ciència de Materials de Barcelona, ICMAB (CSIC), Campus UAB, 08193 Bellaterra, Spain

${ }^{2}$ Instituto de Microelectrónica de Barcelona, IMB-CNM (CSIC), Campus UAB, 08193 Bellaterra, Spain

KEYWORDS: carbon films, silica, sol-gel, adhesion, electrochemical sensors, hybrid materials

\section{Abstract}

Thin carbon films deposited on technologically relevant substrates, such as silicon wafers, can be easily implemented in miniaturized electrochemical devices and used for sensing applications. However, a major issue in most carbon films is the weak film/substrate adhesion that shortens the working device lifetime. This paper describes the facile preparation of robust thin carbon films on silicon/silicon oxide substrates by one-pot sol-gel synthesis. The improved adherence of these carbon films is based on the 
incorporation of silica through the controlled synthesis of a resorcinol/formaldehyde gel modified with aminopropyltriethoxysilane. The films demonstrate excellent adhesion to the silicon/silicon oxide substrate, good homogeneity, excellent electrical conductivity and superior electrochemical performance. Moreover, this approach opens the door to the fabrication of thin carbon film electrodes by photolithographic techniques.

\section{Keywords}

Carbon/silica film, interfacial adhesion, electrical conductivity, electrochemistry

\section{Introduction}

Carbon based materials have attracted much attention as electrodes for electrochemical sensors due to its low cost, wide potential window, relatively inert electrochemistry and electrocatalytic activity in a wide range of redox reactions involving inorganic, organic and biological molecules ${ }^{1}$. Most carbon electrodes are prepared by processing bulk carbonaceous materials such as graphite and glassy carbon $^{2}$ or carbon nanomaterials $^{3}$ including nanotubes ${ }^{4}$ or graphene ${ }^{5}$. The introduction of these carbon materials into an electrode varies from sensor to sensor depending on its uses. For instance, to prepare carbon paste electrodes ${ }^{6}$, which are widely used for research purposes, the carbon particles can be easily dispersed in a paste or a liquid vehicle. By contrast, the industrial mass production of screen printed electrodes (SPE), such as the ones used in glucose test strips for diabetes ${ }^{7}$, requires engineering complex carbon-based inks by 
incorporating binders and other additives to the liquid carrier. The widely used SPEs ${ }^{8}$ are thick-film electrodes which were developed to meet the needs of disposable miniaturized electrochemical probes to enable on-site analyses ${ }^{9}$. Nowadays, a growing trend towards enabling automated on-site monitoring in real time and for extended periods of time has placed miniaturized robust electrodes in the limelight. SPEs are not tailored to meet these specific needs as the presence of binders and other additives are at the origin of an accelerated deterioration of electrode performance. In this context, miniaturized thin-film carbon electrodes are an attractive alternative offering additional advantages such as improved electrochemical performance, thanks to its nearly pure carbon composition, and the possibility of fabrication using robust and well setup photolithographic based processes.

The deposition of high quality carbon films is critical for the electrochemical sensor application and has met three important requirements ${ }^{10}$. Firstly, the deposition procedure should be simple and cost-effective. Secondly, the films have to be robust enough to be patterned by photolithographic techniques, which involve working with reactive solvents and photoresists of different nature. Thirdly, the resulting sensor must be mechanically and chemically robust to withstand exposure to various electrolyte media and multiple electrochemical processes. To fulfill the above-mentioned characteristics, the thin carbon films must demonstrate an excellent interfacial adhesion to the substrate.

A variety of methods have been reported for the preparation of thin carbon films displaying a wide range of structures and properties between those of graphite and 
diamond $^{1,10}$ or even more exotic forms of carbon such as nanotubes ${ }^{11}$ or graphene ${ }^{12}$. Most of these films have been prepared on technologically relevant substrates such as silicon either by depositions in vacuum or by pyrolysis processes of gases ${ }^{13}$ and films prepared from liquid precursors such as polymers ${ }^{14}$ or photoresists ${ }^{15}$. The pyrolysis approach has the advantages of simplicity and low cost and moreover, the so-called pyrolyzed photoresist films (PPF) are perfectly suited for the film patterning by photolithography before pyrolysis. However, a quite common shortcoming of carbon microelectrodes prepared by photolithography is a weak film/substrate interaction, manifested by film flaking during long term operation and this represents the most hampering limitation for sensor applications of these materials.

Chemical bonding between the film and the substrate is essential to ensure a robust construct. Thus, considering the well-known fact that silica films on Si substrates show strong film/substrate adhesion due to the formation of siloxane chemical bonds (-Si-O-Si-) ${ }^{16}$, one route to improve the adherence of carbon film on Si substrates is by the incorporation of silica into the carbon matrix. Interestingly, we reported that pyrolyzed organic gels are appealing materials to fabricate electrodes for electrochemical sensors ${ }^{17}$ and moreover sol-gel chemistry offers the possibility of mixing the different precursors from carbon and silica at molecular level resulting in homogeneous composite (carbon/silica) hybrid materials ${ }^{18}$. In particular, Song et al. have reported on porous carbon/silica films on Si substrates fabricated by spin coating a sol composed of both silica and phenol/formaldehyde, followed by a pyrolysis step ${ }^{18 b}$, pointing out that the addition of silica into the carbon matrix significantly improved the 
adhesion of the film on the substrate. Moreover, conductivity of these carbon/silica films up to $40 \mathrm{wt} \%$ silica content remained comparable to that of carbon inks commonly used for the preparation of screen printed electrodes. In their approach the carbonaceous and silica sols were synthesized separately and then mixed together. Such approach is time-consuming, requiring a multiple-step process carried out over several days.

Here, we report on the fabrication of hybrid carbon/silica thin films with enhanced interfacial adhesion to silicon/silicon oxide substrates by a one-step sol-gel route. Resorcinol and formaldehyde are used as the carbon source whilst aminopropyltriethoxysilane (APTES) was selected as the silica source. A homogeneously mixed solution of these three components formed a gel that is spin-coated onto the substrate and converted into a carbon/silica film by controlled pyrolysis. The synthetic conditions to prepare uniform films on silicon/silicon oxide substrates are then optimized. Surface morphology, electrical conductivity as well as electrochemical performance of these films are systematically investigated. The films display remarkable enhanced interfacial adhesion to silicon wafers and superior electrochemical properties. In addition, the films could be photolithographically patterned for the fabrication of robust carbon films electrodes. 


\section{Experimental Section}

\subsection{Reagents and Materials}

The following chemicals were purchased from Sigma-Aldrich and used as received: resorcinol (m- $\mathrm{C}_{6} \mathrm{H}_{4}(\mathrm{OH})_{2}, 99 \%$ pure), formaldehyde water solution $\left(\mathrm{CH}_{2} \mathrm{O}, 37 \mathrm{wt}\right.$.\%, methanol stabilized), (3-aminopropyl)trimethoxysilane (APTES $\geq 98 \%$ ), ethanol (96\% pure), acetic acid $\left(\mathrm{CH}_{3} \mathrm{COOH}, 99.7 \%\right.$ pure), Potassium ferricyanide and potassium ferrocyanide $99 \%$ pure and potassium nitrate (purity $>99.0 \%$ ), also from Sigma-Aldrich were employed for the electrochemical characterization .

$500 \mu \mathrm{m}$ thick 4-inch silicon wafers were thermally oxidized at $1000^{\circ} \mathrm{C}$ to get a $1 \mu \mathrm{m}$ thick silica layer, labeled as silicon/silicon oxide wafer. The oxide-terminated silicon wafer was diced into $2 \times 2 \mathrm{~cm}^{2}$ substrates. Prior to use, the substrate was thoroughly cleaned in hot piranha solution and rinsed in distilled water.

\subsection{Preparation of Carbon/Silica films}

The preparation of carbon/silica films involves three steps, namely: 1) sol preparation, 2) spin-coating an organic/silica film and 3) carbonization. The nature of the sol is critical for the successful deposition of the films by spin-coating. The influence of the sol in the final thickness of the film is presented in detail in section 2.3. Table 1 lists the composition of the sols employed for producing the carbon films. In step 1), APTES was first dissolved in ethanol or an ethanol/acetic acid mixture in a glass container, and 
then resorcinol and formaldehyde were added successively. The mixture was stirred continuously at room temperature until a clear homogeneous solution was formed. The resorcinol/APTES molar ratio was varied between 1 and 4 . The relative molar content of resorcinol and APTES are indicated in the sample labeling by the two digits following carbon silica, respectively. The labeling of the films shown in Table 1 also takes into account if relatively high $\left(\mathrm{A}_{\mathrm{H}}\right)(785 \mu \mathrm{L})$ or low quantities $\left(\mathrm{A}_{\mathrm{L}}\right)(50 \mu \mathrm{L})$ of acetic acid were used in the preparation of the sol, adding $A_{H}$ and $A_{L}$ respectively in the label. For comparison, a carbon film, labeled C-A, was also prepared using a sol containing only carbon precursor.

Table 1. Sol compositions, details of the gelation process and resulting film thickness.

\begin{tabular}{|c|c|c|c|c|c|c|c|c|c|}
\hline Samples & $\begin{array}{c}\mathrm{R} \\
(\mathrm{g})\end{array}$ & $\begin{array}{c}\mathrm{F} \\
(\mathrm{ml})\end{array}$ & $\begin{array}{c}\text { APTES } \\
(\mathrm{ml})\end{array}$ & $\begin{array}{c}\text { Ethanol } \\
(\mathrm{ml})\end{array}$ & $\begin{array}{c}\text { HAc } \\
(\mu \mathrm{l})\end{array}$ & $\begin{array}{c}\text { Reaction } \\
\text { time }(\mathrm{h})\end{array}$ & $\begin{array}{c}\text { Gelation } \\
\text { time }(\mathrm{h})\end{array}$ & $\begin{array}{c}\text { Film thickness } \\
(\mathrm{nm})\end{array}$ & $\begin{array}{c}\text { Cracks on } \\
\text { films }\end{array}$ \\
\hline CS11-A $_{\mathrm{H}-1}$ & 0.4 & 0.54 & 0.84 & 2 & 785 & $\mathrm{x}$ & 0.15 & $\mathrm{x}$ & $\mathrm{x}$ \\
\hline CS11-A $_{\mathrm{H}}$ & 0.4 & 0.54 & 0.84 & 4 & 785 & 1 & 10 & $\sim 400$ & No \\
\hline CS21-A $_{\mathrm{H}}$ & 0.4 & 0.54 & 0.42 & 2 & 785 & 1 & 24 & $\sim 400$ & No \\
\hline CS41-A $_{\mathrm{H}}$ & 0.4 & 0.54 & 0.21 & 2 & 785 & 24 & 72 & $\sim 400$ & No \\
\hline CS41-A $_{\mathrm{L}}$ & 0.4 & 0.54 & 0.21 & 2 & 50 & 1 & 10 & $\sim 400$ & No \\
\hline CS41 & 0.4 & 0.54 & 0.21 & 2 & & 0.15 & 0.5 & $\sim 800$ & No \\
\hline C-A & 0.4 & 0.54 & & 2 & 785 & 120 & 168 & $\sim 350$ & No \\
\hline
\end{tabular}

x: unprocessable; CS: carbon silica; R: resorcinol; F: formaldehyde; HAc: acetic acid; Reaction time: the time before spin-coating the sol

In step 2) the sols were spin-coated onto $2 \times 2 \mathrm{~cm}^{2}$ silica/silica oxide substrate. Then, gels were deposited by spin coating using rotation speeds from $1000 \mathrm{rpm}$ to $4000 \mathrm{rpm}$. We observed that the average film thickness before pyrolysis decreased when increasing the rotation speed, tending to level off above $3000 \mathrm{rpm}$. In order to obtain reproducible resorcinol/formaldehyde/ $\mathrm{SiO}_{2}$ films, the spin-coating with the sols was 
always performed at 4000 rpm for $45 \mathrm{~s}$.

The viscosity of the sols, which is closely related with its composition, dramatically increases with reaction time and plays a decisive role in the quality of the coated film and its final thickness. In order to obtain continuous and crack-free films, the viscosity of the sols at different reaction times was measured with a HAAKE RheoStress RS600 rheometer in velocity control mode with a shear rate of $2880 \mathrm{~s}^{-1}$ during 30 seconds at 20 ${ }^{\circ} \mathrm{C}$. Sols with viscosities ranging from 6 to $10 \mathrm{mPa} \cdot \mathrm{s}$ resulted in good quality crack-free films with thicknesses between 400 and $800 \mathrm{~nm}$. However, spinning sols with viscosities higher than $11 \mathrm{mPa} \cdot \mathrm{s}$ produced after pyrolysis cracked films thicker than $1000 \mathrm{~nm}$ (see figure S1). The viscosities were adjusted to suitable values by earefully controlling reaction times at room temperature before spinning. The suitable reaction times that were used to obtain crack-free $\mathrm{C} / \mathrm{SiO}_{2}$ films of around $400 \mathrm{~nm}$ thick are included in Table 1 for all the sol compositions.

In step 3), immediately after spin-coating, the gels were placed in an oven at $60^{\circ} \mathrm{C}$ for more than 4 hours for gel aging. Afterwards, they were placed in a quartz tube and pyrolyzed under $\mathrm{Ar}+\mathrm{H}_{2}(95 \%+5 \%)$ atmosphere to convert them into $\mathrm{C} / \mathrm{SiO}_{2}$ films. For carbonization, the furnace temperature was raised to $1000^{\circ} \mathrm{C}$ at a rate of $200^{\circ} \mathrm{C} / \mathrm{h}$, maintaining it at this temperature for 2 hours and then switching the power off to let the furnace cool down to room temperature. During the pyrolysis process, the gas flow rate was $100 \mathrm{~cm}^{3} / \mathrm{min}$. 


\subsection{Film characterization}

The chemical compositions and the nature of the $\mathrm{C}$ and Si bonds of the surface of $\mathrm{C} / \mathrm{SiO}_{2}$ films were analyzed by X-ray photoelectron spectroscopy (XPS) employing AlKa radiation. Scanning electron microscopy was used to study the chemical homogeneity of the films. The surface morphology of the $\mathrm{C} / \mathrm{SiO}_{2}$ films was observed by optical microscopy and atomic force microscopy (AFM) using an Agilent 5100 equipment and a KLA profilometer. The thickness of the spin-coated films before and after carbonization was measured with the profilometer on a zone of the film that had been intentionally scratched with a razor blade (see Figure S1 for a representative 3D profilometric image of a measured film after pyrolysis). The microstructure of the films was studied by Scanning Electron Microscopy at 10 kV (Carl Zeiss Auriga-40 and FEI Quanta 200). A cross section of the film and the substrate was obtained with Focussed Ion Beam equipment (Zeiss 1560XB Cross Beam) at $30 \mathrm{KV}$ and 50 pA using Ga ions. The interfacial adhesion of carbon-based and carbon-silica films to Si substrates was assessed by observing the eventual detachment of the films from the substrate after submitting them to an ultrasonic treatment of 3 minutes in an acetone bath. The interfacial adhesion was also characterized by additional peeling test. Before performing the test the substrates were glued on a microscope glass slide using silver paste. A piece of a transparent tape (MagicTM from 3M) was scotched onto the film and then peeled off while holding the glass slide. 
Four-point probe measurements were carried out to get determine the sheet resistance of the $\mathrm{C} / \mathrm{SiO}_{2}$ films. Three measurements were performed on different areas of each sample and the film thickness determined on an area of $200 \mu \mathrm{m} \times 200 \mu \mathrm{m}$ by profilometry. From the profilometric measurement, the maximum, the minimum and the average value were considered to calculate the resistivity values from the sheet resistance. The resistivity value was determined from the average of those nine values and its standard deviation was considered its error. The electrochemical properties of these $\mathrm{C} / \mathrm{SiO}_{2}$ films were investigated by assessing the cyclic voltammetric behavior of the ferricyanide/ferrocyanide redox couple using a Autolab unit with GPES software (Metrohm-Autolab B.V., The Netherlands). In order to carry out these measurements, the film area to be used as the working electrode was defined by gluing a $3 \mathrm{~mm}$ diameter cylindrical plastic cuvette to the film surface using thermoplastic silicone. Electrical contact was done by fixing an $\mathrm{Al}$ wire on one corner of the film with silver paste (see Figure S2 for a schematic drawing of the set-up). When carrying out the measurements, a silver wire pseudo-reference electrode and a stainless steel wire counter electrode were immersed in the cuvette to complete the electrochemical cell.

\section{Results and Discussion}

\subsection{Sol-gel synthesis of $\mathrm{C} / \mathrm{SiO}_{2}$ films on $\mathrm{Si}$ substrates}

As can be seen from Table 1, the incorporation of APTES into resorcinol/formaldehyde system accelerates gelation. Keeping constant the acetic acid content, the gelation time 
decreased significantly by increasing the relative content of APTES from 0.2 to 0.5 . For instance, CS11- $\mathrm{A}_{\mathrm{H}-1}$ gelled after only $\sim 0.15 \mathrm{~h}$ when it was synthesized in $2 \mathrm{~mL}$ ethanol as the samples CS21- $\mathrm{A}_{\mathrm{H}}$, CS41- $\mathrm{A}_{\mathrm{H}}$ and C-A, but crack-free films could not be obtained with this sol. To facilitate sol handling and processing into a film by spin coating, gelation rate was thus slowed down by doubling the volume of solvent. Acids are catalysts for both resorcinol/formaldehyde and silica sol-gel processes. However, the gelation rate of resorcinol/formaldehyde/APTES system was observed to speed up increase dramatically by decreasing the acetic acid content. For instance, in the case of the $\mathrm{C} / \mathrm{SiO}_{2} \mathrm{CS} 41$ film series, the gelation time decreased from $72 \mathrm{~h}$ to 30 min with the absence of $785 \mu \mathrm{L}$ acetic acid. This paradoxical behavior can be understood if one takes into account that gels are also base-catalyzed and that the presence of an amino group in APTES provides base characteristics to the compound. The amino group catalyzes inter- or intra-molecular reactions between silane molecules and silanol groups to form siloxane bonds, one of the necessary steps of the resorcinol/formaldehyde/APTES gelation process. The slowing down in the gelation rate induced by the addition of acetic acid occurs because it neutralizes the basic character of the amino group weakening its catalytic effect. 
The carbonization processes involved a large reduction of the vertical film dimensions. Taking sample CS21- $\mathrm{A}_{\mathrm{H}}$ as an example, the average thickness of the film decreased from $\sim 900 \mathrm{~nm}$ to $\sim 400 \mathrm{~nm}$, i.e. $\sim 55 \%$ reduction in thickness. Taking into account the fact that the $\mathrm{SiO}_{2}$ xerogel shrinks less than the resorcinol/formaldehyde xerogel during pyrolysis, it was expected that shrinkage decreases for samples containing more $\mathrm{SiO}_{2}$. Indeed, in the case of sample CS11- $\mathrm{A}_{\mathrm{H}}$, which contains the largest amount of $\mathrm{SiO}_{2}$, a $\sim 50 \%$ reduction in thickness was observed. Even though the presence of acetic acid in the CS41 sample series significantly slowed down the gelation rate, we did not observe any influence of this parameter on the film shrinkage. Interestingly, thanks to the strong interfacial adhesion between $\mathrm{C} / \mathrm{SiO}_{2}$ film and the silicon/silicon oxide substrate, none of the studied $\mathrm{C} / \mathrm{SiO}_{2}$ films showed shrinkage of the lateral dimensions regardless the dimensions of the used substrates. In spite of the important shrinkage resulting from pyrolysis the $\mathrm{C} / \mathrm{SiO}_{2}$ films are expected to present a substantial porosity. Even though this could not be characterized by standard methods due to the small mass of the films, we investigated the porosity of bulk $\mathrm{C} / \mathrm{SiO}_{2}$ materials by nitrogen adsorption porosimetry. For instance, in the case of the bulk CS41 monoliths the porosity is characterized by the presence of pores below $3 \mathrm{~nm}$ (micropores) and a surface area of

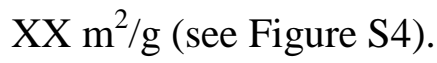

\subsection{Interfacial adhesion between the films and the Si substrate}

In order to test the adhesion of the films to the substrate we established a test providing though conditions for the material in the context of its final application as 
electrochemical sensor in liquid solution. Two films (with and without $\mathrm{SiO}_{2}$ ) were immersed in acetone and placed in an ultrasonic bath for 3 min. Figure 1 shows the images of the films after the test. It can be clearly observed that the pure carbon film (C-A), peels off from the Si substrate, demonstrating a very poor interfacial adhesion. By contrast, the carbon-silica film $\left(\mathrm{C} 41-\mathrm{A}_{\mathrm{L}}\right)$ shows no flaws after the ultrasonic treatment, indicating that addition of $\mathrm{SiO}_{2}$ significantly enhances the film interfacial adhesion. We hypothesize that this fact is directly related to the formation of Si-O-Si covalent bonds between the $\mathrm{SiO}_{2}$ xerogel and the $\mathrm{SiO}_{2}$ layer on the silicon substrate. Moreover, it can also be concluded from Figure 1 that a molar concentration of 25\% of APTES with respect to resorcinol creates a $\mathrm{C} / \mathrm{SiO}_{2}$ thin film with a strong enough interfacial adhesion to ensure robust films. In fact, except for C-A film, no film detachment was observed in any of the hybrid $\mathrm{C} / \mathrm{SiO}_{2}$ film samples listed in Table 1.
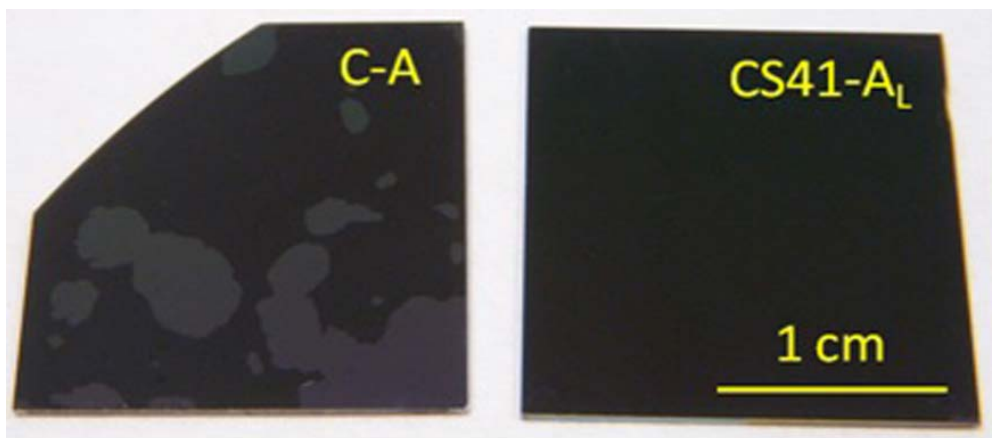

Figure 1. Representative images of pure carbon and $\mathrm{C} / \mathrm{SiO}_{2}$ films on $\mathrm{Si}$ substrates after ultrasonic treatment in acetone bath for $3 \mathrm{~min}$. 
More evidence on the enhanced adhesion of the $\mathrm{C} / \mathrm{SiO}_{2}$ films compared to $\mathrm{C}$ films was obtained with a peeling tests using scotch tape (see Movies S1 and S2) The Movies clearly show that the $C$ film is peeled off from the substrate with the tape while this is not the case for the $\mathrm{C} / \mathrm{SiO}_{2}$ film.

\subsection{Topography of the carbon thin-films}

Figure 2(A) shows a representative optical image of a $\mathrm{C} / \mathrm{SiO}_{2}$ thin film and the corresponding surface profile recorded with a profilometer. It shows that the film surface is not flat as it presents roughness at two scales. A wave-like roughness morphology with an amplitude of about $50 \mathrm{~nm}$ and a periodicity of about $50 \mu \mathrm{m}$ onto which a surface roughness of smaller vertical and lateral dimensions could be detected. This is a common feature of spin coated films and has been related to the rapid drying of the deposited film during the spin-coating process, especially when a volatile solvent with low boiling point such as ethanol is used. ${ }^{19}$ In addition, we found that the wave-like roughness becomes more pronounced for thicker films. For instance, the wave amplitude increased from 40 to $70 \mathrm{~nm}$ as the thickness of the $\mathrm{CS} 21-\mathrm{A}_{\mathrm{H}} \mathrm{C} / \mathrm{SiO}_{2}$ film increased from 400 to $800 \mathrm{~nm}$. It was also found that in films of different composition but comparable thicknesses, the $\mathrm{SiO}_{2}$ content had little effect on the wave amplitude. At this point, it should be emphasized that the motivation of our work was the development of developing $\mathrm{C} / \mathrm{SiO}_{2}$ films that can to be further patterned by photolithographic techniques into microelectrodes for electrochemical sensing. The 
$\sim 50 \mathrm{~nm}$ wavelike roughness is expected to have a negligible influence on the patterning process considering the overall $\mathrm{C} / \mathrm{SiO}_{2}$ film thickness (between $400-800 \mathrm{~nm}$ ) and the usual thickness of the photoresists required to produced patterns in the micron range (between 1-5 $\mu \mathrm{m}$ ).
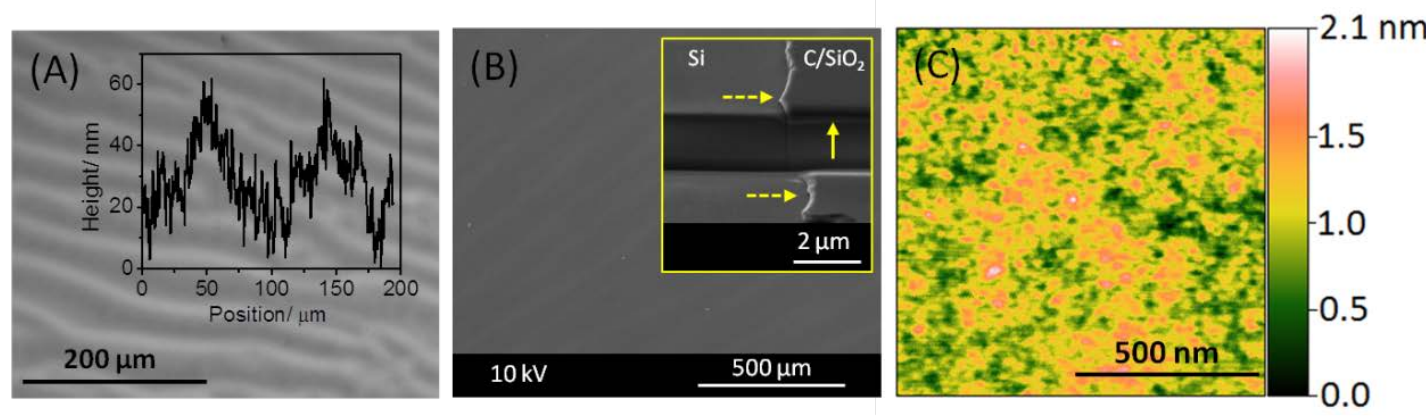

Figure 2. Representative optical (A), SEM (B) and AFM (C) images of the $\mathrm{C} / \mathrm{SiO}_{2}$ thin films. The inset of (A) is the extracted surface profile scanned by profilometer. The inset of (B) is the SEM image of a cross-section of the film created by intentionally scratching the film from top to bottom (see yellow dotted arrows) and a cross-section of the film and the substrate along the left-right direction performed using a FIB (yellow arrow).

Figure 2(B) shows a characteristic SEM image of a film in planar view which displays the already mentioned wave-like roughness and the absence of cracks. The inset of Figure 2(B) shows a cross section of the film in the vertical direction, obtained by intentionally scratching it (see yellow dotted arrows) and a cross-section of the film and the Si substrate along the horizontal direction, created using a focused ion beam equipment (see yellow arrow). It is important to stress that the creation of these cross-sectional features did not result in crack formation at the interface or the surface of the film, providing further evidence of its robustness.

Atomic force microscopy (AFM) was used to analyze the surface roughness of the 
$\mathrm{C} / \mathrm{SiO}_{2}$ films with an increased lateral resolution. Figure 2 (BC) shows a typical AFM image recorded on the CS41 sample, for which a surface roughness value of around 0.2 nm was obtained. The surface roughness measured by AFM became larger in the films with higher $\mathrm{SiO}_{2}$ content. For instance, the roughness value increases up to ca. $1 \mathrm{~nm}$ for the sample CS11- $\mathrm{A}_{\mathrm{H}}$ with the largest $\mathrm{SiO}_{2}$ content. Nevertheless, for the targeted application, the roughness of these $\mathrm{C} / \mathrm{SiO}_{2}$ films can be considered small and its homogeneity excellent as any phase separation between carbon and $\mathrm{SiO}_{2}$ components was not observed at the macro and microscales by scanning electron microscopy analysis using the backscattered electrons mode, which reveals an intensity contrast when changes in the average atomic number exist in the studied materials. However, one can get further insight into the microstructure of the $\mathrm{C} / \mathrm{SiO}_{2}$ films thanks to the selective etching of $\mathrm{SiO}_{2}$ in a $2 \mathrm{M} \mathrm{NaOH}$ aqueous solution. After immersing the films for 2 hours in the solution, the SEM images reveal a highly branched dendritic-like structure with the voids between the branches, formerly occupied by $\mathrm{SiO}_{2}$, with lateral dimensions below the micron range (See Fig. S3). Extending the immersion time results in the complete detachment of the film and makes the solution acquire a dark tone as a result of the $\mathrm{C}$ debris in suspension. These observations indicate that the film consists of two independent intermixed networks of $\mathrm{C}$ and $\mathrm{SiO}_{2}$, resulting from the polymerization of resorcinol and formaldehyde and the hydrolysis and condensation of APTES, respectively. Such interwoven $\mathrm{C}$ and $\mathrm{SiO}_{2}$ networks are responsible for the increased robustness of the films thanks to the strong attachment of $\mathrm{SiO}_{2}$ to the substrate through silanol bonds. Regarding the nature of the intermixed networks, we 
considered the possibility of the amine moiety present in APTES participating in the enhanced robustness of the films by creating a chemically bonded $\mathrm{C} / \mathrm{SiO}_{2}$ interface, as it has been reported that alkyl amines can be bonded to glassy carbon (cite here: Deinhammer, R. S., Ho, M., Anderegg, J. W. \& Porter, M. D. Electrochemical oxidation of amine-containing compounds: a route to the surface modification of glassy carbon electrodes. Langmuir 10, 1306-1313 (1994); Nasir, T., Zhang, L., Vila, N., Herzog, G. \& Walcarius, A. Electrografting of 3-Aminopropyltriethoxysilane on a Glassy Carbon Electrode for the Improved Adhesion of Vertically Oriented Mesoporous Silica Thin Films. Langmuir 32, 4323-4332 (2016)). We could not find evidence of C-N-Si bonding from XPS measurements. These measurements revealed that $\mathrm{N}$ was not present in the $\mathrm{C}-\mathrm{SiO}_{2}$ films, even though it was detected in the gel films before pyrolysis (see Figure S4), indicating a thermal decomposition of the amine moieties.

\subsection{Sheet Resistance of the $\mathrm{C} / \mathrm{SiO}_{2}$ Thin-Films}

The addition of APTES made the deposition of $\mathrm{C} / \mathrm{SiO}_{2}$ thin films much easier and more efficient in terms of reaction time than that of pure carbon films and also strongly improved their interfacial adhesion to silicon/silicon oxide substrate. However, the presence of $\mathrm{SiO}_{2}$ hinders the charge transport through carbon, resulting in a higher electrical resistivity of $\mathrm{C} / \mathrm{SiO}_{2}$ compared to that of the pure carbon film. Figure 3 presents the electrical conductivity of the different $\mathrm{C} / \mathrm{SiO}_{2}$ thin films. The electrical conductivities reported in the literature for carbon xerogel and aerogel materials pyrolyzed at $1000^{\circ} \mathrm{C}$ vary from 1 to $40 \mathrm{~S} \cdot \mathrm{cm}^{-1} \cdot{ }^{20}$ Here, the electrical conductivity for the 
pure carbon xerogel film is $\sim 30 \mathrm{~S} \cdot \mathrm{cm}^{-1}$. The electrical conductivity decreases with the increase of the $\mathrm{SiO}_{2}$ content. For instance, the conductivities measured for the films CS41- $\mathrm{A}_{\mathrm{H}}$ and CS11- $\mathrm{A}_{\mathrm{H}}$ that, which contain the lowest and highest amount of $\mathrm{SiO}_{2}$ in the CS- $\mathrm{A}_{\mathrm{H}}$ series, are around 5 and $18 \mathrm{~S} \cdot \mathrm{cm}^{-1}$, respectively. Nevertheless, the conductivity of these $\mathrm{C} / \mathrm{SiO}_{2}$ films are quite comparable to or even more conductive than that of typical screen printed carbon inks used in electrochemical sensing whose reported values are between $1-10 \mathrm{~S} \cdot \mathrm{cm}^{-1} \cdot{ }^{21}$ One can expect that the conductivity measurements are affected by the existence of the $50 \mathrm{~nm}$ wavelike roughness. An estimation of the relative error related to such variations for a typical thickness of $400 \mathrm{~nm}$ results in a relative error of about $12 \%$, in agreement with the larger errors experimentally determined, except for CS41 films.

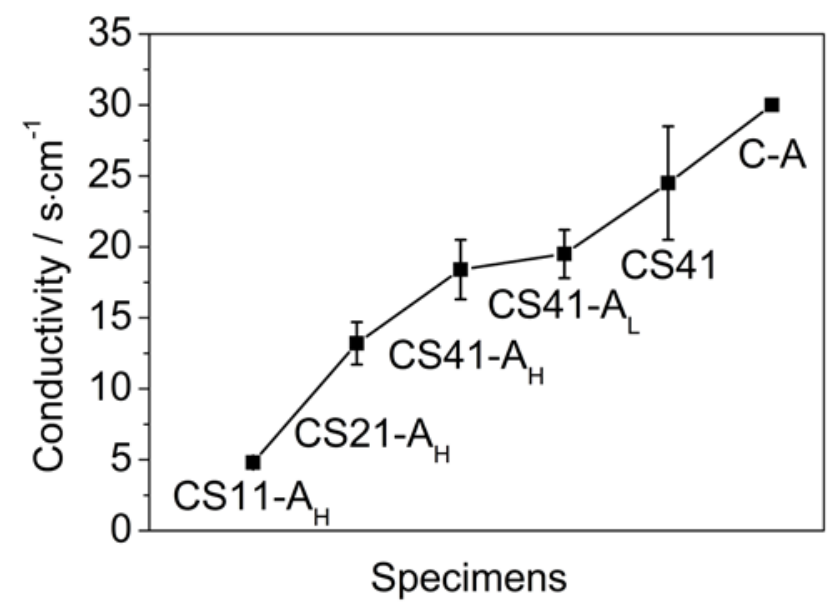

Figure 3. Electrical conductivities of $\mathrm{C} / \mathrm{SiO}_{2}$ films containing different of $\mathrm{SiO}_{2}$ content or prepared from sols with different concentrations of acetic acid.

Figure 3 also shows that the film prepared from a sol without acetic acid (CS41) shows a somewhat higher electrical conductivity than those with the same $\mathrm{C} / \mathrm{SiO}_{2}$ composition but prepared from sols containing acetic acid $\left(\mathrm{CS} 41-\mathrm{A}_{\mathrm{H}}\right.$ and CS41- $\left.\mathrm{A}_{\mathrm{L}}\right)$. This 
conductivity change is due to differences in the surface chemical composition of the films, which were revealed by a comparative XPS analysis of the CS41 and CS41- $\mathrm{A}_{\mathrm{H}}$ films. Figure 4 presents the normalized XPS spectra corresponding to the $\mathrm{C} 1 \mathrm{~s}$, $\mathrm{O}$ 1s and Si 2p of these two films. The CS41- $\mathrm{A}_{\mathrm{H}}$ film shows higher relative intensities of the Si 2p and O 1s peaks and correspondingly a lower relative intensity of the $\mathrm{C} 1$ s peak. In Figure 4c one can also note that the shapes of the Si 2p spectra of the two films are quite different. Using Gaussian curve fitting, the Si 2p spectrum of both films can be decomposed into two peaks ascribed to oxidized silicon and centered at around 103.4 $\mathrm{eV}$ and $101.9 \mathrm{eV}$ (see inset of Figure 4c) corresponding to sample CS41. The 103.4eV peak corresponds to $\mathrm{SiO}_{2}$ whereas the $101.9 \mathrm{eV}$ peak falls in the binding energy range of the suboxides $\left(\mathrm{SiO}_{\mathrm{x}}\right.$, with $\left.\mathrm{x}<2\right)$. Interestingly, the relative $\mathrm{SiO}_{\mathrm{x}}$ content is much higher in CS41 film than in CS41- $\mathrm{A}_{\mathrm{H}}$ film. This supports our hypothesis that the presence of acetic acid alters the gelation process of APTES by blocking the catalytic effect of amino group making the gelation slower. 

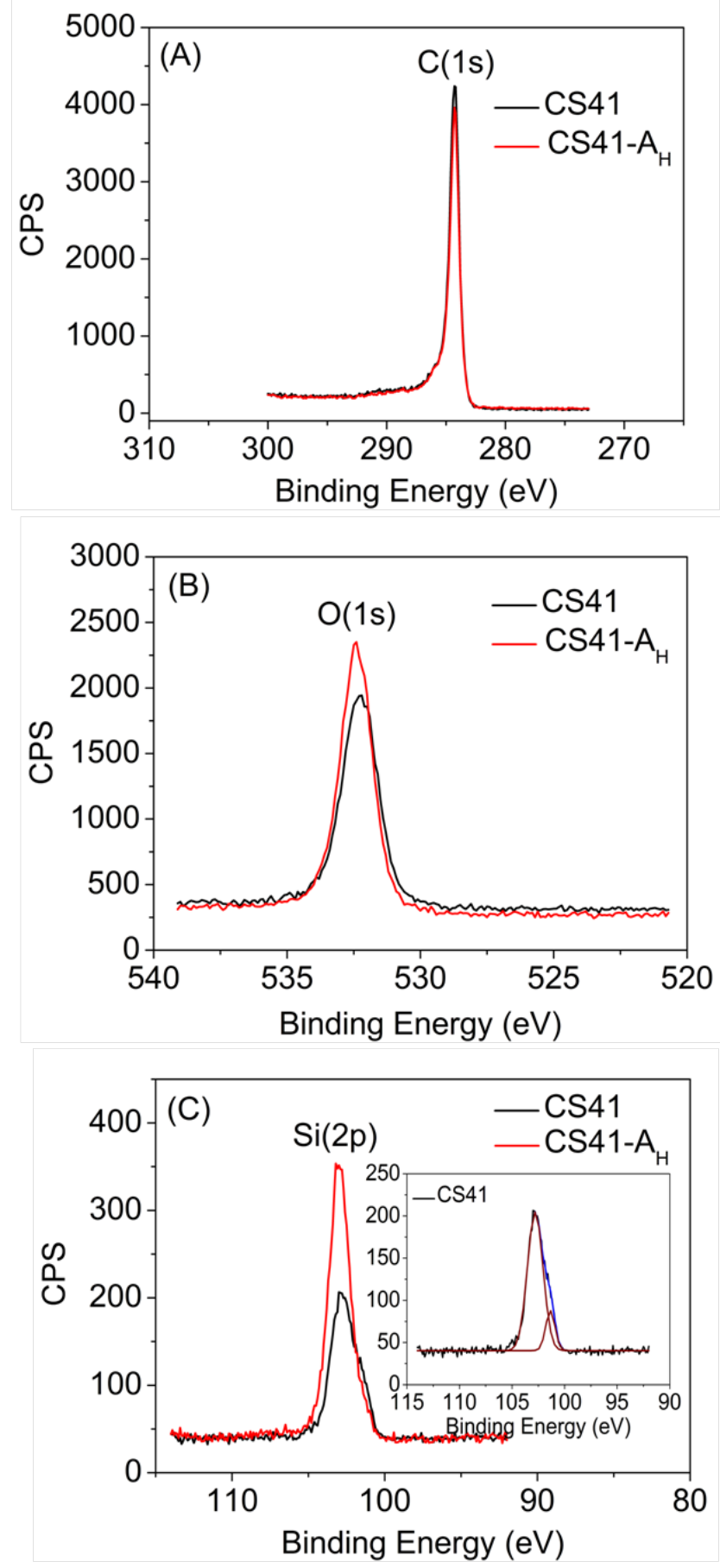

Figure 4. XPS spectra of showing the binding energies of $C$ 1s (A), O 1s (B) and Si $2 \mathrm{p}(\mathrm{C})$ for the CS41 and CS41- $\mathrm{A}_{\mathrm{H}}$ films.

Why does the system without acetic acid result in a $\mathrm{C} / \mathrm{SiO}_{2}$ film (CS41) with somewhat lower content of $\mathrm{SiO}_{2}$ on the surface? We believe that it has to do with the above the presence of acetic acid which slows the gelation of $\mathrm{APTES}$ network.

In order to get a better insight into this mechanism and avoiding the complexity of 
gelation studies in films we investigated the formation of bulk monolithic gels from the CS41 and CS41- $\mathrm{A}_{\mathrm{H}}$ sols. The monitoring of the resorcinol/formaldehyde/APTES sols without and with acetic acid at different stages of the gelation process gave valuable information to understand the differences observed in the films (see images of different stages of the process in Figure S3). On one hand, at a given reaction time the color of the CS41 sol was darker than that of CS41- $\mathrm{A}_{\mathrm{H}}$ sol, confirming the faster gelation of CS41 system. On the other hand, during the ageing stage following the gelation process, we observed that the gel of CS41- $\mathrm{A}_{\mathrm{H}}$ showed a homogeneous appearance whereas the color of the CS41 gel was lighter at the bottom and darker at the top. As we know, $\mathrm{SiO}_{2}$ gels are normally white and resorcinol/formaldehyde gels are red in color. The homogeneous color of the CS41- $\mathrm{A}_{\mathrm{H}}$ system during the whole process reveals a simultaneous formation of resorcinol/formaldehyde and APTES networks. By contrast, for the CS41 system the gel was first white and then gradually turned to red but showing a color gradient from the top to the bottom of the gel, evidencing the initial gelation of APTES later followed by the formation of resorcinol/formaldehyde gel. Thus, in the CS41 system, the initially formed $\mathrm{SiO}_{2}$ network tends to form clusters (cite: J. D. Wright and N. A. J. M. Sommerdijk, Sol Gel Materials Chemistry and Applications CRC Press, London 2001, page 20.) because it is base-catalyzed, and those are dragged towards the bottom of the container due to its higher density and the resulting gel is not homogeneous. If this phenomenon is extrapolated to the formation of gel films by spin coating, one can understand the higher relative $\mathrm{SiO}_{2}$ content at the surface of the CS41- $\mathrm{A}_{\mathrm{H}}$ film and its lower conductivity. 


\subsection{Electrochemical Performance of the $\mathrm{C} / \mathrm{SiO}_{2}$ Thin-Films}

Figure 5 displays typical voltammograms recorded with the $\mathrm{C}_{\mathrm{SiO}}$ films. Quasi-reversible electrochemical responses were recorded, showing an anodic to cathodic peak current ratio of around 1. It was also observed that the peak to peak potential separation $\left(\Delta E_{P}\right)$ appreciably decreases from ca. $167 \mathrm{mV}$ to $137 \mathrm{mV}$ when the molar fraction of APTES in the films decreased from 0.5 to 0.2 while, by contrast, the faradic peak currents increased from $10 /-11 \mu \mathrm{A}$ to $26 /-29 \mu \mathrm{A}$, respectively. The higher peak current and lower $\Delta E_{P}$ indicate a larger active surface area and a faster electron transfer at the electrolyte $\mathrm{C} / \mathrm{SiO}_{2}$ film interface. This is the expected behavior taking into account the lower sheet resistance of the films with lower silica content. Surprisingly, pure carbon films showed a similar peak current but larger $\Delta E_{P}$ compared to those recorded with CS41 films. This might be related to the differences in the surface chemistry and the interaction of the redox probes with the surface, which is known to greatly influence the electron transfer and so the resulting electrochemical performance $^{22}$. 


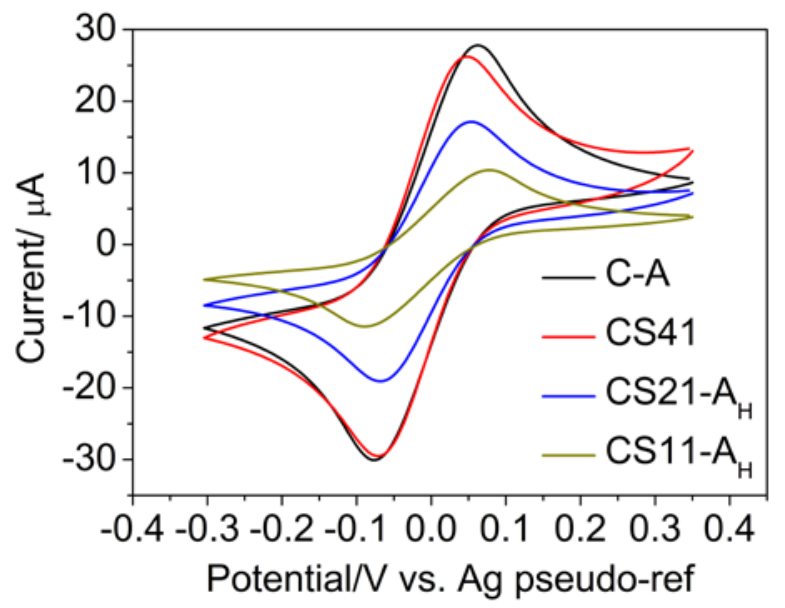

Figure 5. Cyclic voltammograms recorded with $\mathrm{C} / \mathrm{SiO}_{2}$ films with different silica content, in a $0.1 \mathrm{M} \mathrm{KNO}_{3}$ solution containing $1 \mathrm{mM}$ ferri/ferrocyanide redox couple. Scan rate: $50 \mathrm{mV} / \mathrm{s}$.

The influence of the scan rate on the peak currents was studied with the CS41 film. The recorded peak currents (see Figure S4) are proportional to the square-root of the scan rate in the range of $10-100 \mathrm{mV} / \mathrm{s}$, which is the usual behavior of a diffusion-controlled electrode process.

Figure 6 compares the cyclic voltammetric responses of a porous carbon xerogel paste electrode $\left(\mathrm{C}_{\mathrm{P}} \mathrm{PE}\right)$ as prepared in our previous publication ${ }^{17}$, a commercial screen printed graphite electrode (DRP 110 from DropSens S.L, Spain; SPGE), a commercial glassy carbon electrode (CH Instruments Inc., US; GCE) and the $\mathrm{CS} 41 \mathrm{C} / \mathrm{SiO}_{2}$ film electrode. At a scan rate of $50 \mathrm{mV} / \mathrm{s}, \Delta E_{P}$ values of around $210,181,107$ and $137 \mathrm{mV}$ were obtained, respectively. Compared to $\mathrm{C}_{\mathrm{P}} \mathrm{PE}$ and SPGE, a much smaller $\Delta E_{P}$ value was recorded with $\mathrm{CS} 41 \mathrm{E} / \mathrm{SiO}_{z}$ film electrode, indicating a relatively faster electron transfer at the ES41 film electrolyte interface. The heterogeneous electrochemical rate constant $k^{0}$ was also calculated for the four electrodes tested using the Nicholson method (eq.1) ${ }^{23}$. 


$$
\varphi=\boldsymbol{k}^{0}[\pi D n v F /(R T)]^{-\mathbf{1} / \mathbf{2}}
$$

where $D$ is the diffusion coefficient of potassium ferricyanide in $0.1 \mathrm{KNO}_{3}$ (ca. $7.01 \mathrm{x}$ $\left.10^{-6} \mathrm{~cm}^{2} \cdot \mathrm{s}^{-1}\right)^{24}, n$ is the number of electrons involved in the electrochemical reaction, which in this case is equal to one, $v$ is the scan rate in $\mathrm{V} / \mathrm{s}, F$ is the faraday constant, $R$ is the universal gas constant and $T$ the absolute temperature. The dimensionless kinetic parameter, $\varphi$, is first determined using the following analytical equation:

$$
\varphi=\left(-0.6288+0.0021 * \Delta E_{p}\right) /\left(1-0.017 * \Delta E_{p}\right)
$$

The electrochemical performance of the different types of electrodes, described by the $\Delta E_{P}$ and $k^{0}$ values evaluated in a $1 \mathrm{mM}$ potassium ferricyanide solution, is reported in Table 2. The $k^{0}$ for CS41 film, $0.0017 \mathrm{~cm} / \mathrm{s}$, displays quite favorable electron transfer rate compared to SPGE and $\mathrm{C}_{\mathrm{P}} \mathrm{PE}$, whose estimated $k^{0}$ values were $0.0008 \mathrm{~cm} / \mathrm{s}$ and $0.0005 \mathrm{~cm} / \mathrm{s}$, respectively. In addition, the calculated $k^{0}$ values for CS21- $\mathrm{A}_{\mathrm{H}}$ and CS11- $\mathrm{A}_{\mathrm{H}}$ films were estimated to be $0.0012 \mathrm{~cm} / \mathrm{s}$ and $0.0010 \mathrm{~cm} / \mathrm{s}$, respectively. These values indicate slower transfer kinetics of films with larger $\mathrm{SiO}_{2}$ contents, but these are still significantly higher than those calculated for SPGE and $\mathrm{C}_{\mathrm{P}} \mathrm{PE}$. Additionally, it is known that the electron transfer rate $k^{0}$ value typically ranges from $10^{-4}$ to $10^{-2} \mathrm{~cm} / \mathrm{s}$ at carbon based electrodes ${ }^{25}$, depending on the structure and morphology of carbon materials. The CS41 film electrode underperforms the electrochemical behavior of the commercial GCE, which is as manifested by its smaller $\Delta E_{P}$ and a larger $k^{0}$ value of $0.0032 \mathrm{~cm} / \mathrm{s}$. Both the GCE and the CS41 film electrodes have in common that they do not incorporate any extra additives to the functional materials and show an enhanced performance compared to that of $\mathrm{C}_{\mathrm{P}} \mathrm{PE}$ and SPGE, which by contrast contain additives 
such as paraffin and curing binders, respectively.

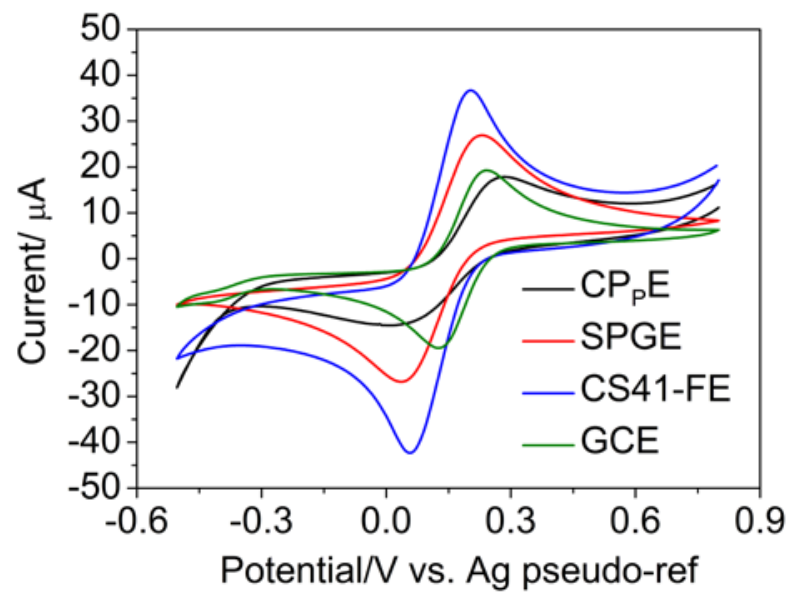

Figure 6. Cyclic voltammograms recorded in a $0.1 \mathrm{M} \mathrm{KNO}_{3}$ solution containing 1 $\mathrm{mM}$ ferri/ferrocyanide redox couple at $\mathrm{C}_{\mathrm{P}} \mathrm{PE}$, SPGE, GC and CS41 at a scan rate of $50 \mathrm{mV} / \mathrm{s}$.

Table 2. Peak separation and electron transfer rate $k^{0}$ value for different electrodes in a $0.1 \mathrm{M} \mathrm{KNO}_{3}$ solution containing $1 \mathrm{mM}$ ferri/ferrocyanide redox couple

\begin{tabular}{|l|c|c|}
\hline \multicolumn{1}{|c|}{ Electrode type } & $\Delta \mathrm{E}_{\mathrm{P}}(\mathrm{mV})$ & $\mathrm{k}_{0}(\mathrm{~cm} / \mathrm{s})$ \\
\hline $\mathrm{CS} 41 \mathrm{C} / \mathrm{SiO}_{2}$ & 137 & 0.0017 \\
\hline $\mathrm{CS} 21-\mathrm{A}_{\mathrm{H}} \mathrm{C} / \mathrm{SiO}_{2}$ & 155 & 0.0012 \\
\hline $\mathrm{CS} 11-\mathrm{A}_{\mathrm{H}} \mathrm{C} / \mathrm{SiO}_{2}$ & 167 & 0.0010 \\
\hline $\mathrm{SPGE}$ & 181 & 0.0008 \\
\hline $\mathrm{C}_{\mathrm{P}} \mathrm{PE}$ & 210 & 0.0005 \\
\hline $\mathrm{GCE}$ & 107 & 0.0032 \\
\hline
\end{tabular}




\section{Conclusions}

This study describes the deposition of carbon thin films on silicon/silicon oxide substrates by a one-pot resorcinol/formaldehyde/APTES sol-gel spin coating approach. The inclusion of acid in the sol influences the deposition and the final properties of the films. The interfacial adhesion between carbon films and silicon/silicon oxide substrate was can be significantly enhanced by the addition of a $\mathrm{SiO}_{2}$ precursor to the sol formulation. Then-carbon/silica films display a uniform appearance but below the micron range present a phase segregation between carbon and silica in the form of interwoven dendritic-like networks. Compared to pure carbon xerogel films, the addition of $\mathrm{SiO}_{2}$ was not detrimental to the functional properties of the films, showing conductivities larger than those reported for typical screen printed inks. Cyclic voltammetry studies demonstrate the great potential of this material in electroanalytical chemistry, with the additional advantage of its prospective application in the fabrication of carbon/silica thin-film microelectrodes by photolithographic processes. For such application, CS41 appears as the most suitable among the materials studied herein, as it presents the highest conductivity and a short reaction time that allows obtaining films only 10 minutes after preparing the sol. 


\section{Supporting information}

Profilometry of $\mathrm{C}-\mathrm{SiO}_{2}$ film; electrochemical testing setup; influence of acetic acid in the gelation of Resorcinol-Formaldehide/APTES sols; XPS spectra;cyclic volatmmetries at different scan rates.

\section{Acknowledgements}

G. Antorrena from the Laboratorio de Microscopias Avanzadas of the Instituto de Nanociencia de Aragón is acknowledged for performing XPS analysis. This research was partially funded by, the European Union's $7^{\text {th }}$ Framework Programme (FP7/2007-2013) under grant agreement number 614155, the Spanish Ministry of Economy and Competitiveness in cofounding with the European Social Funds through the MAT2012-35324 project, the "Severo Ochoa" Programme for Centres of Excellence in R\&D (SEV- 2015-0496) and the Generalitat de Catalunya (2014SGR213, 2014SGR1645). The Chinese Scholarship Council fellowship (201206240033) to P.N. and the COST Action MP1202 are also acknowledged.

\section{References}

1. (a) McCreery, R. L., Advanced carbon electrode materials for molecular electrochemistry. Chemical Reviews 2008, 108 (7), 2646-2687; (b) Zhang, W.; Zhu, S. Y.; Luque, R.; Han, S.; Hu, L. Z.; Xu, G. B., Recent development of carbon electrode materials and their bioanalytical and environmental applications. Chemical Society Reviews 2016, 45 (3), 715-752.

2. Kinoshita, K., Carbon : electrochemical and physicochemical properties. New York etc. : John Wiley \& Sons: New York [etc.], 1988. 
3. (a) Baptista, F. R.; Belhout, S. A.; Giordani, S.; Quinn, S. J., Recent developments in carbon nanomaterial sensors. Chemical Society Reviews 2015, 44 (13), 4433-4453; (b) Mao, X.; Rutledge, G. C.; Hatton, T. A., Nanocarbon-based electrochemical systems for sensing, electrocatalysis, and energy storage. Nano Today 2014, 9 (4), 405-432.

4. Banks, C. E.; Compton, R. G., New electrodes for old: from carbon nanotubes to edge plane pyrolytic graphite. Analyst 2006, 131 (1), 15-21.

5. Brownson, D. A. C.; Kampouris, D. K.; Banks, C. E., Graphene electrochemistry: fundamental concepts through to prominent applications. Chemical Society Reviews 2012, 41 (21), 6944-6976.

6. Švancara, I.; Vytřas, K.; Kalcher, K.; Walcarius, A.; Wang, J., Carbon Paste Electrodes in Facts, Numbers, and Notes: A Review on the Occasion of the 50-Years Jubilee of Carbon Paste in Electrochemistry and Electroanalysis. Electroanalysis 2009, 21 (1), 7-28.

7. Newman, J. D.; Turner, A. P. F., Home blood glucose biosensors: a commercial perspective. Biosensors and Bioelectronics 2005, 20 (12), 2435-2453.

8. Dominguez Renedo, O.; Alonso-Lomillo, M. A.; Arcos Martinez, M. J., Recent developments in the field of screen-printed electrodes and their related applications. Talanta 2007, 73 (2), 202-219.

9. Wang, J., Decentralized electrochemical monitoring of trace metals: From disposable strips to remote electrodes: Plenary lecture. The Analyst 1994, 119 (5), 763-766.

10. Niwa, O., Electroanalytical chemistry with carbon film electrodes and micro and nano-structured carbon film-based electrodes. Bulletin of the Chemical Society of Japan 2005, 78 (4), 555-571.

11. Wang, C.; Zhang, J.; Ryu, K.; Badmaev, A.; De Arco, L. G.; Zhou, C., Wafer-Scale Fabrication of Separated Carbon Nanotube Thin-Film Transistors for Display Applications. Nano Letters 2009, 9 (12), 4285-4291.

12. Zhang, L.; Shi, Z.; Wang, Y.; Yang, R.; Shi, D.; Zhang, G., Catalyst-free growth of nanographene films on various substrates. Nano Research 2011, 4 (3), 315-321. 
13. McFadden, C. F.; Russell, L. L.; Melaragno, P. R.; Davis, J. A., Low-temperature pyrolytic carbon films: electrochemical performance and surface morphology as a function of pyrolysis time, temperature, and substrate. Analytical Chemistry 1992, 64 (14), 1521-1527.

14. Jung, C.-H.; Kim, W.-J.; Jung, C.-H.; Hwang, I.-T.; Khim, D.; Kim, D.-Y.; Lee, J.-S.; Ku, B.-C.; Choi, J.-H., A simple PAN-based fabrication method for microstructured carbon electrodes for organic field-effect transistors. Carbon 2015, 87, 257-268.

15. Kim, J.; Song, X.; Kinoshita, K.; Madou, M.; White, B., Electrochemical studies of carbon films from pyrolyzed photoresist. Journal of the Electrochemical Society 1998, 145 (7), 2314-2319.

16. Bohannan, E. W.; Gao, X. R.; Gaston, K. R.; Doss, C. D.; Sotiriou-Leventis, C.; Leventis, N., Photolithographic patterning and doping of silica xerogel films. Journal of Sol-Gel Science and Technology 2002, 23 (3), 235-245.

17. Gich, M.; Fernandez-Sanchez, C.; Cotet, L. C.; Niu, P.; Roig, A., Facile synthesis of porous bismuth-carbon nanocomposites for the sensitive detection of heavy metals. Journal of Materials Chemistry A 2013, 1 (37), 11410-11418.

18. (a) Ye, L.; Ji, Z.-H.; Han, W.-J.; Hu, J.-D.; Zhao, T., Synthesis and Characterization of Silica/Carbon Composite Aerogels. Journal of the American Ceramic Society 2010, 93 (4), 1156-1163; (b) Song, L.; Feng, D.; Campbell, C. G.; Gu, D.; Forster, A. M.; Yager, K. G.; Fredin, N.; Lee, H.-J.; Jones, R. L.; Zhao, D.; Vogt, B. D., Robust conductive mesoporous carbon-silica composite films with highly ordered and oriented orthorhombic structures from triblock-copolymer template co-assembly. Journal of Materials Chemistry 2010, 20 (9), 1691-1701; (c) Si, M.; Feng, D.; Qiu, L.; Jia, D.; Elzatahry, A. A.; Zheng, G.; Zhao, D., Free-standing highly ordered mesoporous carbon-silica composite thin films. Journal of Materials Chemistry A 2013, 1 (43), 13490-13495.

19. Spangler, L. L.; Torkelson, J. M.; Royal, J. S., INFLUENCE OF SOLVENT AND MOLECULAR-WEIGHT ON THICKNESS AND SURFACE-TOPOGRAPHY OF SPIN-COATED POLYMER-FILMS. Polymer Engineering and Science 1990, 30 (11), 
644-653.

20. Fung, A. W. P.; Wang, Z. H.; Lu, K.; Dresselhaus, M. S.; Pekala, R. W., CHARACTERIZATION OF CARBON AEROGELS BY TRANSPORT MEASUREMENTS. Journal of Materials Research 1993, 8 (8), 1875-1885.

21. See for instance product specifications of commercial carbon inks at http://www.gwent.org/gem_carbon_working.html

22. McCreery, R. L.; McDermott, M. T., Comment on Electrochemical Kinetics at Ordered Graphite Electrodes. Analytical Chemistry 2012, 84 (5), 2602-2605.

23. Nicholso.Rs, THEORY AND APPLICATION OF CYCLIC VOLTAMMETRY FOR MEASUREMENT OF ELECTRODE REACTION KINETICS. Analytical Chemistry 1965, 37 (11), 1351-\&.

24. Griffiths, K.; Dale, C.; Hedley, J.; Kowal, M. D.; Kaner, R. B.; Keegan, N., Laser-scribed graphene presents an opportunity to print a new generation of disposable electrochemical sensors. Nanoscale 2014, 6 (22), 13613-13622.

25. Lee, S. H.; Fang, H. Y.; Chen, W. C.; Lin, H. M.; Chang, C. A., Electrochemical study on screen-printed carbon electrodes with modification by iron nanoparticles in $\mathrm{Fe}(\mathrm{CN})(6)(4-/ 3-)$ redox system. Analytical and Bioanalytical Chemistry 2005, 383 (3), 532-538.

\section{Table Of Contents}




\section{Resorcinol/Formaldehyde/APTES Sol}
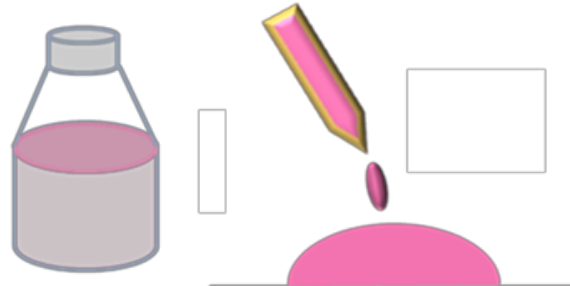

Solvent Evaporation

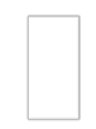

Si Substrate

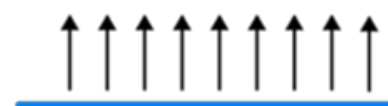

Spinner

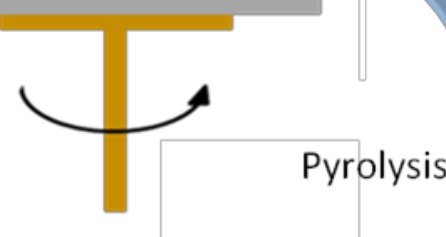

Robust Porous $\mathrm{C}-\mathrm{SiO}_{2}$ film

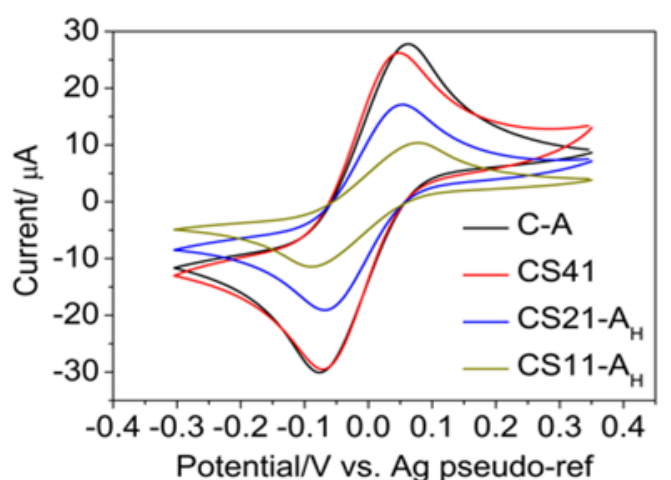

